\title{
A controlled field experiment to investigate the deterioration of earthen heritage by wind and rain
}

J. Richards ${ }^{*} \mathbb{0}$, G. Zhao ${ }^{2}$, H. Zhang ${ }^{1}$ and H. Viles ${ }^{1}$

\begin{abstract}
Earthen heritage constitutes 10\% of sites on the World Heritage List and many of these sites are experiencing extensive deterioration caused by environmental forces, such as wind and rain. This study used a well-established test wall to investigate the impact of environmental conditions on the deterioration of earthen heritage at the remote and under-studied site of Suoyang Ancient City, Gansu Province, China, which is exhibiting widespread deterioration. Test walls have previously been used in earthen heritage research as they allow controlled experiments to be undertaken on complex, realistic structures without risking damage or loss of value to the historic material. This study used portable wind and rain erosion simulation devices to investigate experimentally (i) the comparative effect of wind, sediment-laden wind and wind-driven rain in causing deterioration to earthen heritage and (ii) how the incipient deterioration features produced by wind, sediment-laden wind and wind-driven rain on the test wall relate to the deterioration features recorded on the historic city walls. The test wall was subjected to low, medium and high intensities of clean wind, sediment-laden wind and wind-driven rain. The extent of deterioration produced was measured using repeat, high resolution laser scans before and after each test run. The deterioration features caused by each environmental force were notably different with clean wind removing the loose surface material, sedimentladen wind causing pitting and wind-driven rain causing incipient gullying. These incipient features compare well with more developed features seen on the historic walls. Wind-driven rain caused the greatest amount of deterioration while clean wind caused the least. However, as the frequency and duration of wind events at Suoyang is much greater than those of rain events, wind is likely to play an important role in the deterioration of earthen heritage over annual timescales. These findings show that conservation strategies at rammed earth sites like Suoyang need to address the impact of multiple environmental forces, such as clean wind, sediment laden wind and wind-driven rain.
\end{abstract}

Keywords: Earthen heritage, Deterioration, Field experiment, Northwest China

\section{Introduction}

Earthen heritage sites make up $10 \%$ of the World Heritage List with many of these sites located in arid and semi-arid environments [1]. Despite the universal value of earthen heritage, many sites have, and are continuing to experience, extensive deterioration which threatens to reduce their value [2-4].

\footnotetext{
*Correspondence: jennifer.richards@ouce.ox.ac.uk

1 Oxford Rock Breakdown Laboratory, School of Geography

and the Environment, University of Oxford, Oxford OX1 3QY, UK

Full list of author information is available at the end of the article
}

Earthen heritage can be constructed using a variety of methods including rammed earth, adobe, wattle and daub and cob [5], each of which has its own complex set of material properties [6]. This paper will focus on the deterioration of rammed earth as the sites comprising this material have been less investigated compared to adobe [e.g. 6-11], despite rammed earth experiencing extensive and widespread deterioration [3, 12]. Hereafter, earthen heritage will refer to rammed earth in arid to semi-arid environments unless otherwise stated.

Deterioration of earthen heritage is affected both by material properties and environmental conditions [6]. Variations in material properties across a site (e.g. 
compressive strength and grain size) can help identify areas which may be particularly at risk of future deterioration [12]. However, to limit the extent to which historic material is altered, conservation strategies need to understand how environmental conditions cause deterioration [13].

Previous studies have highlighted the importance of rain, wind and sediment-laden wind as drivers of earthen heritage deterioration, with rain noted as causing the greatest rate of deterioration over short periods of time $[6,14-16]$. Commonly a combination of processes cause deterioration $[6,17]$. Studies have tended to be undertaken either in laboratory experiments where small samples are exposed to controlled environmental conditions [18-20], or in the field where test or historic walls are exposed to natural conditions and monitored after a period of time $[8,16,21]$. In the laboratory, the use of small samples has meant that deterioration has often been measured by weight loss. However, in situ the substrates manifest deterioration features such as scouring, flaking and cracking [12], which cannot be mimicked in laboratory experiments, limiting the extent to which findings from studies in the laboratory can be used to understand deterioration processes on site. In the field, studies have tended to use features of deterioration visible on the walls to infer back to the processes which caused the deterioration [12]. However, as the environmental history of the site since construction tends to be unknown, uncertainty is raised by issues of equifinality, where two different process histories may have caused the same deterioration feature to occur [22]. Furthermore, field studies have tended to be concentrated on a small number of accessible and well-studied sites (e.g. Çatalhöyük, Turkey) [23-25] with many other, more remote sites not being studied limiting the wider applicability of findings.

To design successful conservation strategies (i.e. strategies which reduce the rate of earthen heritage deterioration), a greater understanding of the impact of environmental conditions on a wide range of earthen heritage sites is needed. This study utilised a unique opportunity for researchers to investigate the impact of environmental conditions on the deterioration of earthen heritage at the remote, and under-studied site of Suoyang Ancient City. The site is located on the ancient Silk Road in Gansu Province, northwest China over $900 \mathrm{~km}$ from Lanzhou, the Province capital, and over $150 \mathrm{~km}$ from the town of Dunhuang. The site is now exhibiting widespread deterioration, and the site managers are eager to prevent further loss of valuable ancient earthen architecture. This study uses a field experiment on a test wall in combination with surveys of deterioration features on ancient walls to investigate (i) the comparative effect of wind, sediment-laden wind and rain in causing deterioration to earthen heritage and (ii) how the incipient deterioration features produced by wind, sediment-laden wind and wind-driven rain on the test wall related to the deterioration features recorded on the historic city walls.

\section{Methods \\ Site description}

Suoyang Ancient City (锁阳城), hereafter known as Suoyang, is an archaeological site located on the ancient Silk Road in remote, semi-arid northwest China. It was built from rammed earth in the Han (206 BC-220 AD) and Tang (618-907AD) dynasties and consists of inner and outer city walls, a monastery, stables, archery platforms and extensive irrigation channels (Fig. 1). It was enlisted as part of the Silk Roads World Heritage Site in 2014 as an exceptional example of a communication and frontier defence settlement along the eastern part of the Silk Roads.

The site was abandoned $\sim 400$ years ago due to a decline in overland trade and the avulsion of the nearby river away from the city. The remains of the city walls now exhibit a variety of deterioration features caused by the interaction of wind, sediment transport and rain with the earthen walls, including flaking, undercutting, polishing and scouring as well as the formation of gullies, cracks, fractures, slumps and collapses (see Fig. 1 for examples).

Research by the Dunhuang Academy (unpublished) found the thickness of the rammed earth layers at Suoyang varies between 8 and $24 \mathrm{~cm}$ and the natural density of the walls ranges between 1.55 and $1.77 \mathrm{~g} \mathrm{~cm}^{-3}$. The grain size distribution of the historic earthen material is polymodal with peaks in grain size $<75 \mu \mathrm{m}$ and between 100 and $250 \mu \mathrm{m}$ and is positively skewed. Additional materials (such as red willows) were found in the walls but only in localised areas.

The site is a challenging setting for research due to its remoteness, its exposure to an extreme continental climate and lack of environmental and historical data from the site. However, since 2015 an experimental area has been established to the east of the main site, comprising several test walls, which allows experimental research into the impact of the environment and conservation strategies on earthen heritage to be undertaken.

\section{Environmental conditions}

According to the Dunhuang Academy, annual rainfall at Suoyang can vary between 30 and $75 \mathrm{~mm}$ with the majority of rainfall occurring between March and September and little rainfall in the winter months. The prevailing easterly wind is strongest in the summer months with westerlies also occurring from September to November. For an overview of regional climate and recent changes in climate in northwest China see Sun et al. [26]. 


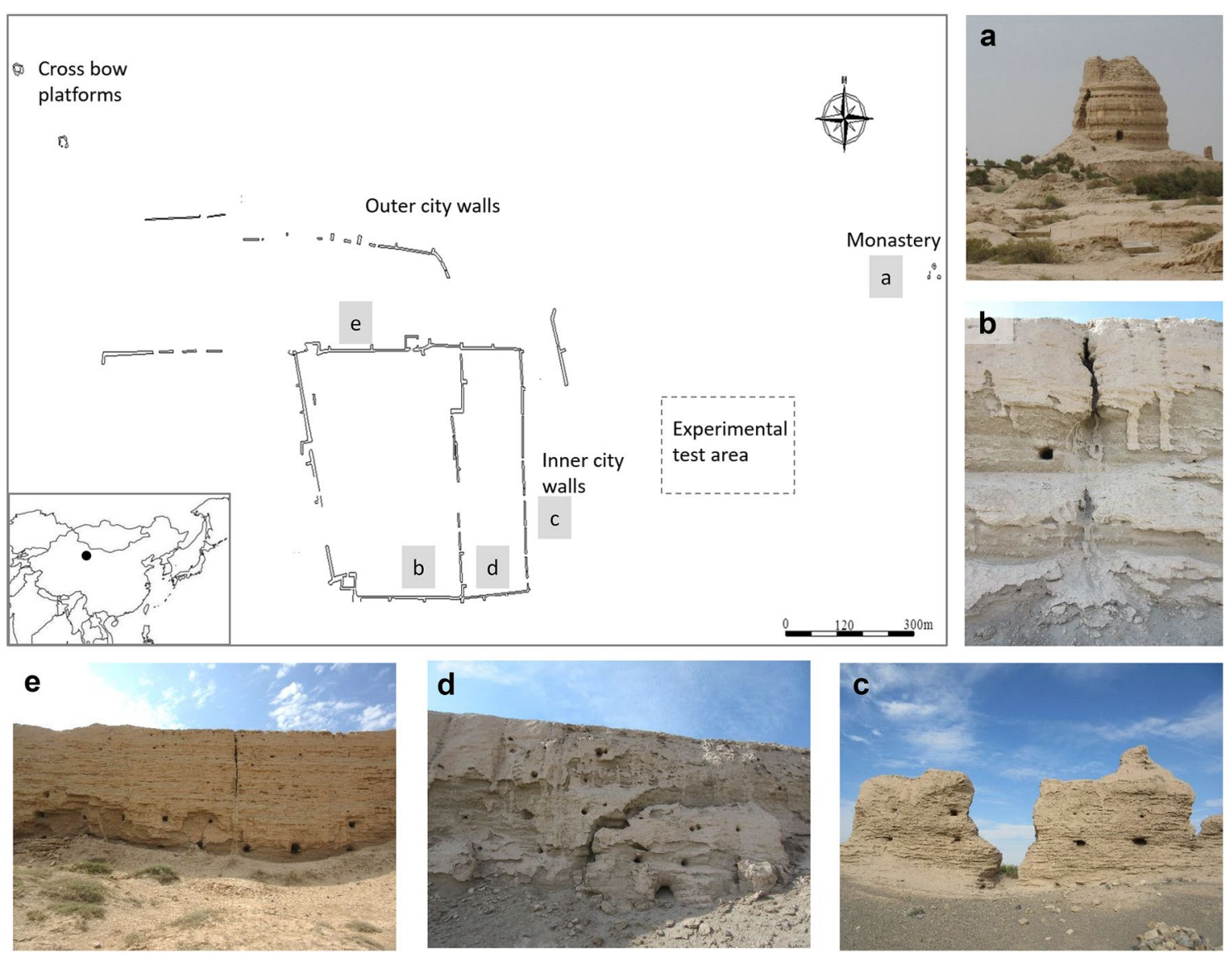

Fig. 1 A site map of Suoyang showing the location of the inner and outer city walls, cross bow platforms, monastery and experimental test area. Inset is the location of Suoyang within China. Photos show $\mathbf{a}$ the Buddhist monastery, $\mathbf{b}$ a gully, $\mathbf{c}$ part of the east inner city wall that has deteriorated into distinct sections, $\mathbf{d}$ the detachment of a section of the southern inner city wall and $\mathbf{e}$ a crack in the southern inner city wall. The locations of photos $\mathbf{a}-\mathbf{e}$ at Suoyang are indicated in grey boxes on the site map

In the absence of long-term climatic data at Suoyang, wind and rain measurements were taken at the site using an automatic weather station in the 6 months preceding and 4 months following this experiment (March to December 2018). Additional wind measurements were recorded at Suoyang between August 2015 and July 2016 following the building of the test walls at the site.

To measure sediment transport at Suoyang, a wedge shape sediment trap orientated to the prevailing wind and a circular sediment trap were deployed between June and September 2018 in an open area also located to the east of the main site. The mass of sediment captured was analysed once a month.

\section{Experimental design}

To investigate the comparative effect of wind, sedimentladen wind and rain in causing deterioration to earthen heritage, this study was undertaken on a small test wall located in the experimental test area. Test walls have previously been used in earthen heritage research (e.g. at Fort Selden) $[4,10,27]$ as they allow experiments to be undertaken under field conditions on complex, realistic structures without risking damage or loss of value to the historic material. Experiments on test walls in the field have advantages over laboratory experiments on large specimens, as test walls are exposed to, and can equilibrate with, complex natural conditions such as fluctuating ground water and changes in internal moisture and salt content which can cause material loss [23], but cannot be realistically simulated in the laboratory. Field experiments also have advantages over monitoring environmental conditions and their impacts on test walls and historic earthen remains, as they are quicker and more easily controlled. Finally, field experiments on test walls are preferable to field experiments on historic earthen walls which would cause unwanted accelerated deterioration. 
The test wall was built in April 2015 by scientists from Dunhuang Academy, specifically to replicate the material properties of the historic walls at Suoyang. It was built from loessic soils taken from Suoyang's wind erosion platform, which had a similar particle size distribution to that of the historic material, and had no additives to best represent Suoyang's material composition. The wall was constructed using traditional ramming techniques by building wooden forms the size of the wall, in which a layer of soil was added and rammed down using a hammer. This process was repeated six times forming a wall measuring $64 \mathrm{~cm}$ high and $76 \mathrm{~cm}$ wide, with a density of $1.70 \mathrm{~g} \mathrm{~cm}^{-3}$. The test wall is thus directly comparable in materials, construction and density to the least deteriorated ancient walls at Suoyang. The wall was then left exposed for 3 years and is now assumed to be in equilibrium with environmental conditions. The deterioration of the wall surface before this study was undertaken was negligible accept for a few small areas at the edge of the wall which exhibited some incipient polishing and scouring features. However, it should be noted that these test walls are not exact replicas of the real site walls, being orders of magnitude younger than the historic site and thus environmental forces may interact differently with the test walls compared to the historic walls. Consequently, all findings on the test walls have been compared with natural processes occurring on the historic walls to assess their validity.

An on-site field deterioration experiment was undertaken on the test wall in August 2018 as part of a wider project investigating potential future conservation methods for Suoyang. Field-based deterioration tests have previously been used in earthen heritage $[3,28]$ and desert environmental studies [29-33] to quantify erosion rates, but have not been used to compare the effectiveness of different environmental forces, nor to compare the incipient deterioration features produced (e.g. gullies) with deterioration features seen on the historic walls. The extent of deterioration is affected by both the erodibility of the test wall (i.e. the cohesiveness of the earthen material) and the erosivity of environmental forces acting on the wall (i.e. the ability of a process to cause erosion). As the erodibility of the test wall is assumed to be constant across all test runs, this experiment compares the difference in erosivity between three environmental forces (wind, sediment-laden wind and wind-driven rain) on earthen heritage.

\section{Test wall preparation}

The top surface $(\sim 0.5 \mathrm{~cm})$ of the front face of the test wall was initially removed with a chisel, exposing fresh material. The surface was then brushed down using a soft brush to remove any loose material. As the building of the test wall was highly controlled and it is assumed to be in equilibrium with the surrounding environment, the material properties of the wall are considered as homogeneous throughout the wall. For each test run, the surface was lightly chiselled again and then brushed to prevent any cumulative impacts of previous test runs on the surface of the wall. Figure $2 \mathrm{a}-\mathrm{c}$ shows the surface topography of the test wall after the initial surface preparation and before the first experimental run. This topography was indicative of the surface roughness before each test run. For erosion studies in desert environments, similar methods of artificially preparing a surface have commonly been used to ensure comparability between test runs [29-33]. However, it should be noted that by exposing fresh material for each test run, the erodibility of the test wall face is likely to be similar to newly exposed areas on the historic wall (e.g. material exposed after processes of flaking, cracking and collapses) but it is likely to be higher in comparison to areas of the historic walls which have weathering features such as crusts present.

The test wall was divided into three $20 \mathrm{~cm} \times 20 \mathrm{~cm}$ test areas using six screws as reference points (Fig. 2). The size and location of test areas at the top of the wall were constrained by the diameter of the funnel on the portable wind tunnel and also by restrictions in lowering the device.

Laser scanning has previously been used to monitor erosion rates at earthen heritage sites over millimetre scales [23, 34, 35] but sub-millimetre, highly detailed repeat laser scanning assessing the impact of environmental processes on earthen heritage deterioration has not been attempted. For this study, before each test run, the test area was laser scanned with a handheld Creaform Handy SCAN $7003 \mathrm{D}^{\mathrm{TM}}$ laser scanner $(0.2 \mathrm{~mm}$ accuracy, $0.050 \mathrm{~mm}$ resolution) using the screws as reference points. In addition, 19 black and white circular targets were used during scanning to improve the accuracy of the laser scanning data. After each test run, the test area was re-scanned using the same process.

\section{Deterioration test}

The test wall was subjected to wind, sediment-laden wind and rain, each at 3 different intensities, resulting in a total of nine test runs (Table 1). The total number of test runs undertaken on the test wall was limited due to each test run requiring the surface of the test wall to be removed. The intensities used in the tests were based on findings in the literature and recorded conditions experienced at Suoyang to simulate a low, medium and high intensity event. Each experimental run focused on a single test area and the other test areas were covered to prevent deterioration occurring. 


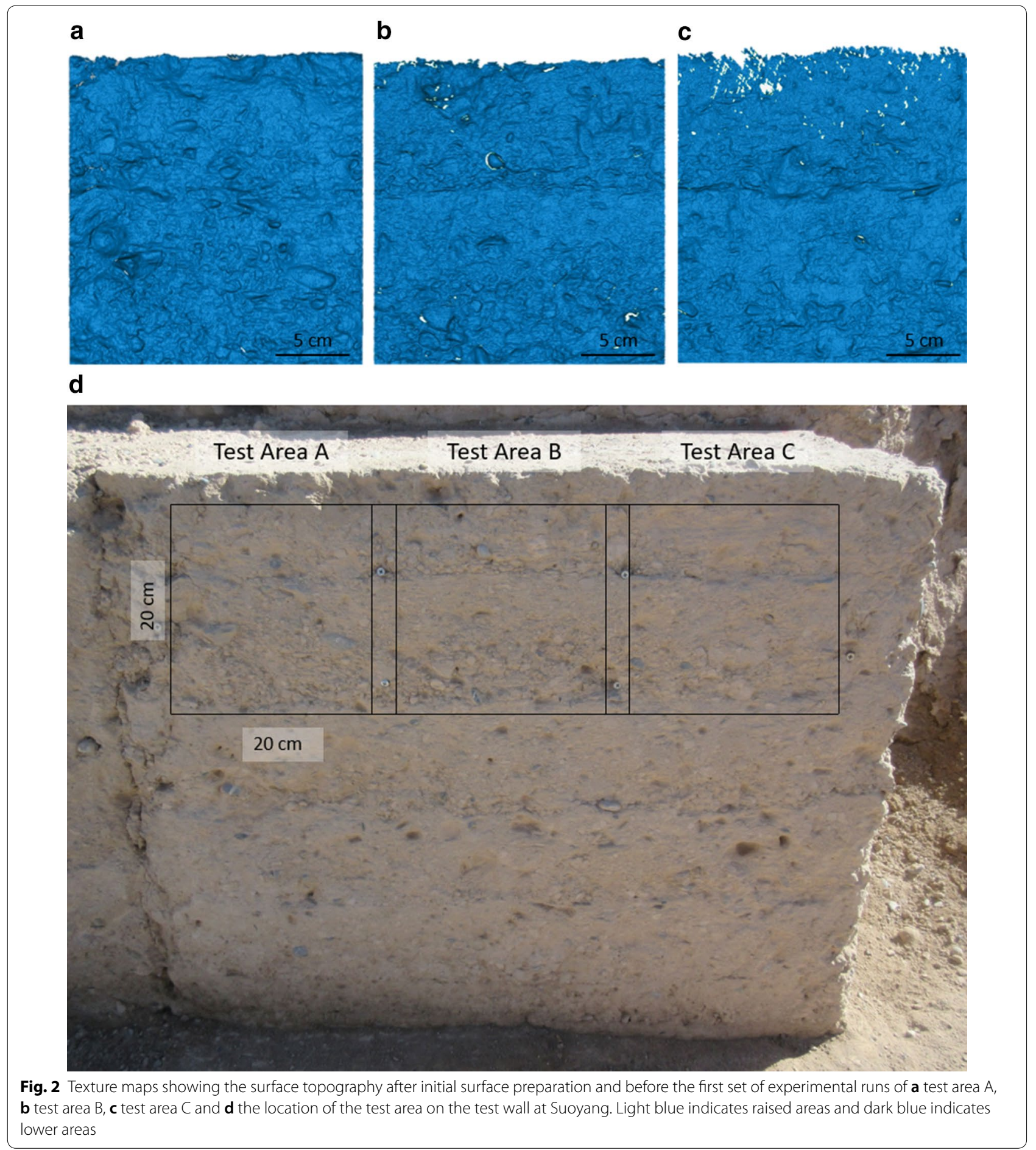

All equipment used in the deterioration tests is patented by the Dunhuang Academy and was specifically developed to undertake field research on earthen heritage deterioration. The equipment was designed to (i) provide greater control over the erosivity of rain and wind than that used in previous research on earthen heritage, such as fans to generate wind [20] and (ii) be easily portable and rugged for use at remote, exposed sites. All equipment used had been calibrated by the manufacturer in a laboratory environment. Given the calibration and the limited total number of runs which could be undertaken on the test walls, all equipment was calibrated in-field 
Table 1 Conditions used in the deterioration test

\begin{tabular}{|c|c|c|c|c|}
\hline Run & Process & Condition & Test area & Rational for condition \\
\hline 1 & \multirow[t]{3}{*}{ Clean wind for 5 min at: } & $12 \mathrm{~m} \mathrm{~s}^{-1}$ & A & Threshold in wind tunnel studies \\
\hline 2 & & $17 \mathrm{~m} \mathrm{~s}^{-1}$ & B & Maximum wind speed in storm at Suoyang (14th-15th Aug 2018) \\
\hline 3 & & $25 \mathrm{~m} \mathrm{~s}^{-1}$ & C & Highest wind speed recorded at Suoyang in 2015-2016 \\
\hline 4 & \multirow{3}{*}{$\begin{array}{l}\text { Sediment-laden wind } \\
80 \mathrm{~g} \mathrm{~min}^{-1} \text { for } 5 \text { min } \\
\text { at: }\end{array}$} & $12 \mathrm{~m} \mathrm{~s}^{-1}$ & A & Threshold in wind tunnel studies \\
\hline 5 & & $15 \mathrm{~m} \mathrm{~s}^{-1}$ & C & Intermediate wind speed as $17 \mathrm{~m} \mathrm{~s}^{-1}$ caused visible damage \\
\hline 6 & & $17 \mathrm{~m} \mathrm{~s}^{-1}$ & B & Maximum wind speed in storm at Suoyang (14th-15th Aug 2018) \\
\hline 7 & \multirow[t]{3}{*}{ Rainfall at $0.2 \mathrm{~L} / \mathrm{min}$ for: } & $20 \mathrm{~s}$ & C & The time at which visible deterioration occurred \\
\hline 8 & & $1 \mathrm{~min}$ & B & Volume of water is equivalent to the 2 nd highest maximum daily rainfall in 2018 at Suoyang \\
\hline 9 & & $2 \mathrm{~min}$ & A & Volume of water is equivalent to the maximum daily rainfall in 2018 at Suoyang \\
\hline
\end{tabular}

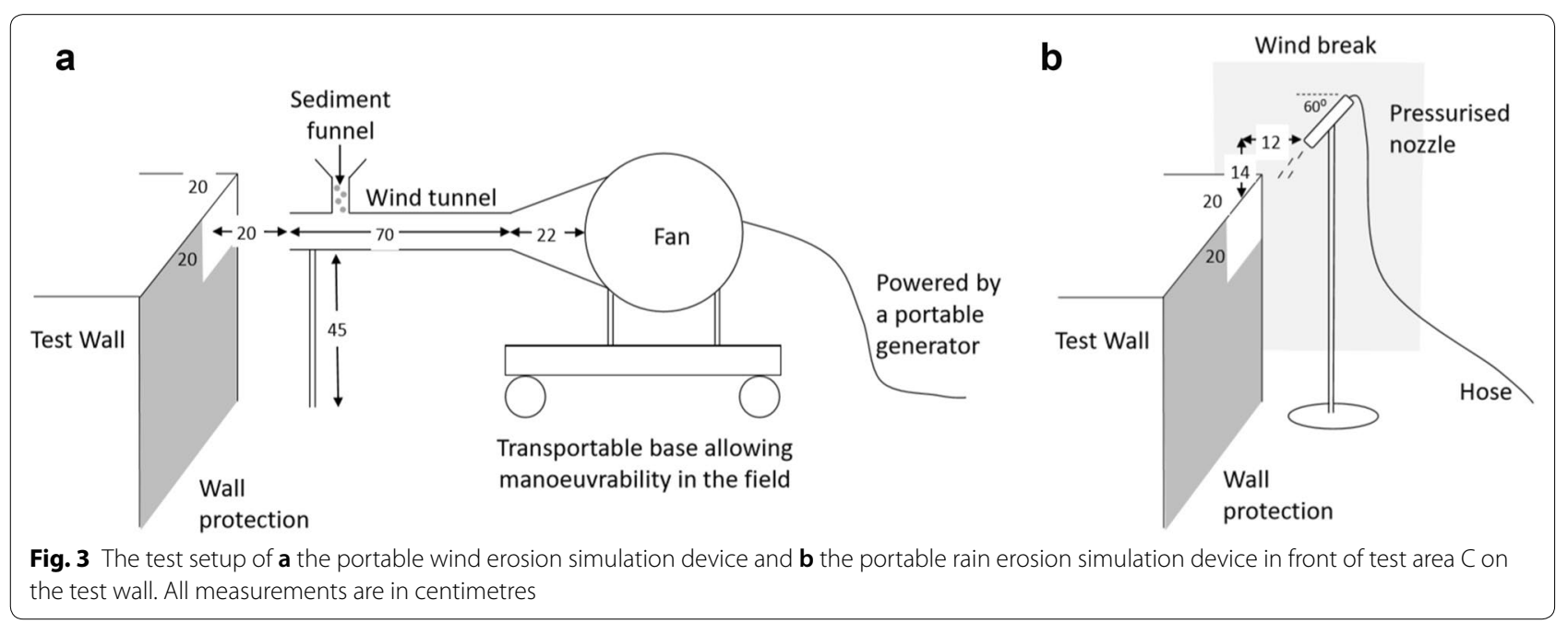

away from the test wall, to ensure that the net impact of the environmental condition was achieved (e.g. the velocity of wind speed produced, the total amount of sediment entrained in the wind per minute and the total amount of water sprayed per minute).

The portable wind erosion simulation device (PWESD) is formed of a generator, fan, sediment funnel and a wind tunnel which is $92 \mathrm{~cm}$ long and $12 \mathrm{~cm}$ wide (Fig. 3a). For each test run, the mouth of the wind tunnel was placed $20 \mathrm{~cm}$ away from the test wall with the wind tunnel perpendicular to the wall to ensure that the test area was evenly subjected the wind generated from the PWESD while minimising the effect from any cross winds that may have occurred during the experiment. At this distance away from the wall, the wind speed was assumed to be constant across the test area. The PWESD was run for $5 \mathrm{~min}$, as in Wang et al. [20], to generate clean winds at 12,17 and $25 \mathrm{~ms}^{-1}$.

The PWESD was also used for the sediment-laden wind tests. The PWESD was set up as for the clean wind tests except for the addition of sediment which was continuously fed through the sediment funnel throughout each test run (Fig. 3a). The sediment used was taken from the surrounding dune deposits and sieved to remove sand particles and organic matter greater than $2 \mathrm{~mm}$ to represent sediment entrained at the site where grain size analysis showed all particles were less than $2 \mathrm{~mm}$. Subsequent particle size analysis showed that the sediment used in the deterioration test was comparable to the normally entrained material, with a polymodal distribution with peaks at $19 \mu \mathrm{m}$, $136 \mu \mathrm{m}$ and $1227 \mu \mathrm{m}$ and was positively skewed. The wall was subjected to wind speeds of 12,15 and $17 \mathrm{~ms}^{-1}$ for 5 min with sediment being entrained in the wind at a rate of $80 \mathrm{~g} \mathrm{~min}^{-1}$ for each test run. A lower maximum wind speed was used for sediment-laden wind, compared to the clean wind test, as the $17 \mathrm{~ms}^{-1}$ wind caused significant visible damage to the test wall. The majority of the sediment was entrained by the wind in the upper half of the wind tunnel causing the upper half of the test area to be subjected to a greater quantity of sediment than the lower half.

The wind-driven rain was created using a Portable Rain Erosion Simulation Device (PRESD) (Fig. 3b). The device 
was set up at a $60^{\circ}$ angle to the test wall to mimic driving rain, with the nozzle $12 \mathrm{~cm}$ away from the wall face. A windbreak was used to prevent cross winds affecting the test area. The device was run using water brought to the site at $0.2 \mathrm{~L} \mathrm{~min}^{-1}$ (the lowest volume possible) for $20 \mathrm{~s}\left(1.9 \mathrm{~mm} \mathrm{~cm}^{-1}\right), 1 \mathrm{~min}\left(4.6 \mathrm{~mm} \mathrm{~cm}^{-1}\right)$ and $2 \mathrm{~min}$ $\left(8.3 \mathrm{~mm} \mathrm{~cm}^{-1}\right)$. The PRESD was designed to provide an even coverage of water to the test area. However, due to the low pressure used, the rainfall was focused in the centre of the test area and the spatial area of rainfall impact increased over time resulting in the amount of rainfall per $\mathrm{cm}^{-1}$ not being directly proportional to the duration of the test run.

\section{Data analysis}

The laser scanning surface spatial grid data was analysed using the software, Geomagic Control. Each point cloud was processed into a 3D mesh. Pre and post-test meshes were aligned manually and then adjusted by the software using the reference screws placed in the wall. The topography of the meshes was then compared to identify any changes to the surface of the wall $\pm 0.2 \mathrm{~mm}$ allowing quantification of the depth of deterioration. The differences between the two scans were mapped allowing the spatial patterns of erosion to be compared between test runs.

\section{Results}

When the wall was subjected to clean wind, the majority of the surface showed no significant change (Fig. 4). During the 12 and $17 \mathrm{~m} \mathrm{~s}^{-1}$ tests we observed no visible changes to the wall surface but the deviation maps showed that loose particles were removed off the wall surface in small localised areas (see the blue areas in Fig. 4a, b). This deflation of material on the wall tended to be from raised areas (Fig. $2 \mathrm{a}-\mathrm{c}$ ) resulting in a smoother surface forming. When the wall was subjected to $25 \mathrm{~m} \mathrm{~s}^{-1}$ wind, erosion occurred on some raised surfaces and also within hollowed areas of the test wall resulting in some visible pitting (Fig. 4c). However, despite the presence of pitting, the total spatial extent of deterioration did not increase (Table 2). The maximum depth of erosion increased with increasing wind speed but the impact was highly localised with less than $1 \%$ of the surface area being significantly deteriorated on all clean wind tests (Table 2).

When the test areas were subjected to sediment-laden wind there was notably more deterioration compared to the clean wind experimental runs (Fig. $4 \mathrm{~d}-\mathrm{f}$ ). This deterioration was concentrated on the upper half of the test areas in association with the design of the PWESD. However, on all sediment-laden wind tests visible pitting occurred and in contrast to when the test walls were exposed to clean wind at the same speeds, the deterioration was not limited to raised areas. For the sedimentladen wind tests, the spatial area of impact and the maximum depth of erosion increased with wind speed with a notable loss of material occurring at $17 \mathrm{~m} \mathrm{~s}^{-1}$ (Table 2). On the lower half of the test areas there were localised areas of deterioration with spatial patterning similar to the patterning on the test areas exposed to $25 \mathrm{~m} \mathrm{~s}^{-1}$ clean wind, i.e. localised removal of material on both the raised areas and in some hollows.

Wind-driven rain caused significant deterioration with the water visibly entraining the material and transporting it down the wall face (Fig. 4g-i). Once a small hollow was formed the water was channelled into this area causing further material to be entrained. Significant deterioration could be seen after $20 \mathrm{~s}$ and the formation of an incipient gully could be seen after $1 \mathrm{~min}$ (Fig. 4g, h). After $2 \mathrm{~min}$, the flow of water down the wall caused the greatest amount of erosion (Table 2) and also further deterioration to the lower sections of the wall (Fig. 4i). Below the incipient gullies, there were some areas which increased in height (shown in yellow in Fig. 4h, i). This could have been caused by the wall swelling as it became saturated by water or by material which was entrained further up the wall being redeposited on the lower sections of the test area.

\section{Discussion}

These findings support previous studies which have found that the extent of deterioration is affected by the environmental conditions earthen heritage is exposed to, with clean wind causing the least and rain causing the most amount of deterioration [3, 18, 20, 36, 37]. However, in contrast to previous studies, the methodology used in this study also resulted in the formation of incipient deterioration features under controlled environmental conditions. More developed versions of these incipient deterioration features are seen on the historic walls at Suoyang (Fig. 5). This suggests that this field based experimental method provides (i) a more realistic deterioration mechanism than using small

\footnotetext{
(See figure on next page.)

Fig. 4 Deterioration caused by $\mathbf{a}-\mathbf{c}$ wind, $\mathbf{d}-\mathbf{f}$ sediment-laden wind and $\mathbf{g}$-i rain with (i) visual observations (Obs.) while the deterioration test was undertaken, (ii) post-test photographs of the test area and iii) the laser scanning deviation map showing changes in surface topography (blue $=$ negative surface change, green $=$ no significant change and yellow = positive surface change), note the difference in the quantitative scale between rows $(\mathrm{mm})$. The letter (A), (B) or (C) refers to the test area the experiment was undertaken on
} 


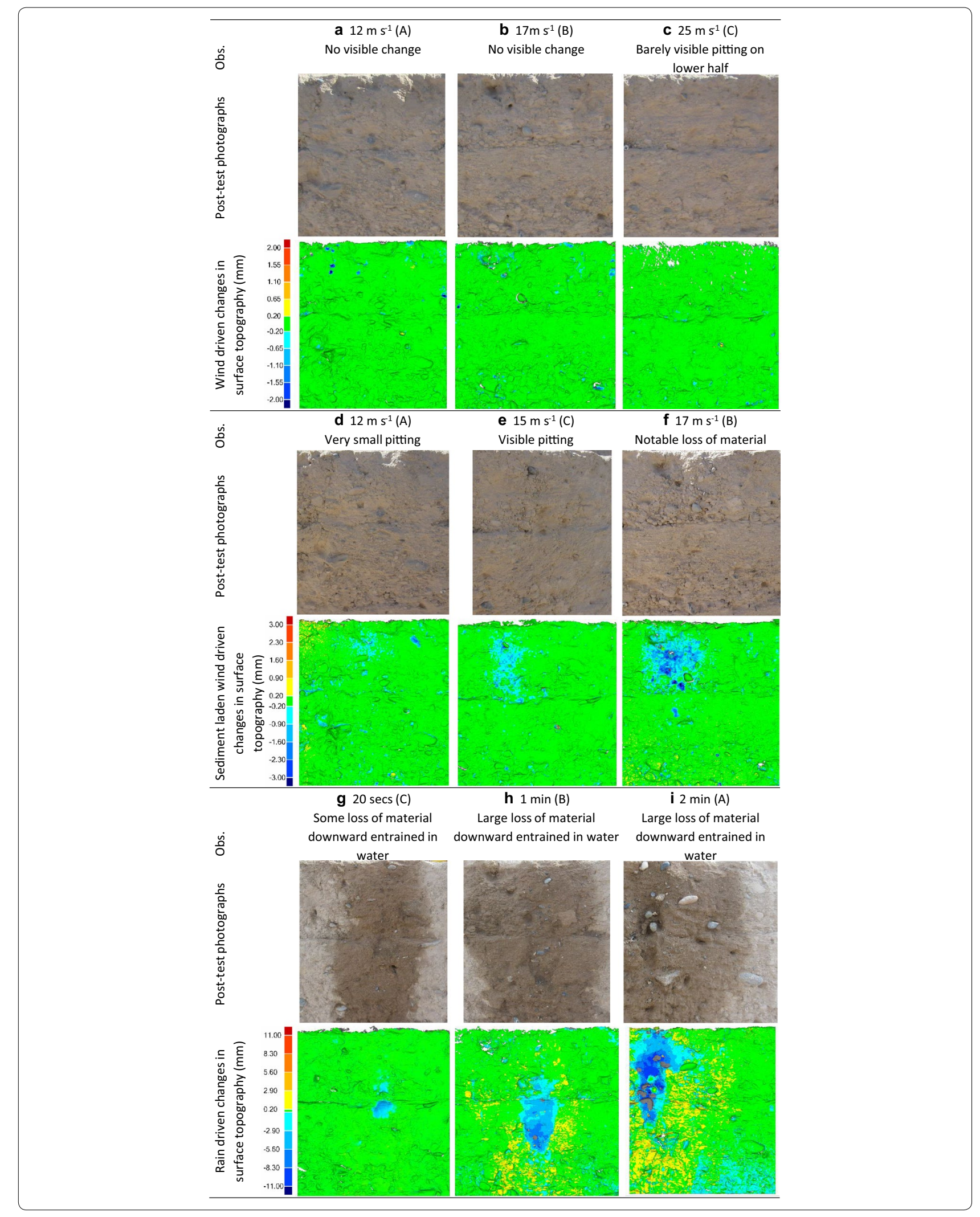

b $17 \mathrm{~m} \mathrm{~s}^{1}(\mathrm{~B})$
No visible change

C $25 \mathrm{~m} \mathrm{~s}^{1}$ (C) 
Table 2 The maximum depth and spatial extent of erosion after deterioration tests

\begin{tabular}{|c|c|c|}
\hline Condition applied to test area & Maximum depth of erosion (mm) & $\begin{array}{l}\text { Area covered by erosion in } \mathrm{mm}^{2} \text { and as a } \\
\text { percentage of total area (blue areas } \\
\text { in Fig. 4) }\end{array}$ \\
\hline \multicolumn{3}{|c|}{ Clean wind for 5 min at the speed of $(\mathrm{m} / \mathrm{s})$} \\
\hline 12 & 6.49 & $228(0.6 \%)$ \\
\hline 17 & 7.90 & $316(0.8 \%)$ \\
\hline 25 & 10.69 & $292(0.7 \%)$ \\
\hline \multicolumn{3}{|c|}{ Laden sediment wind $80 \mathrm{~g} / \mathrm{min}$ for $5 \mathrm{~min}$ at the speed of $(\mathrm{m} / \mathrm{s})$} \\
\hline 12 & 4.29 & $1132(2.8 \%)$ \\
\hline 15 & 11.00 & $1804(4.5 \%)$ \\
\hline 17 & 11.00 & $3576(8.9 \%)$ \\
\hline \multicolumn{3}{|l|}{ Rainfall at $0.2 \mathrm{~L} / \mathrm{min}$ for $(\mathrm{s})$} \\
\hline 20 & 9.24 & $768(1.9 \%)$ \\
\hline 60 & 10.62 & $3956(9.8 \%)$ \\
\hline 120 & 11.20 & $7276(18.2 \%)$ \\
\hline
\end{tabular}

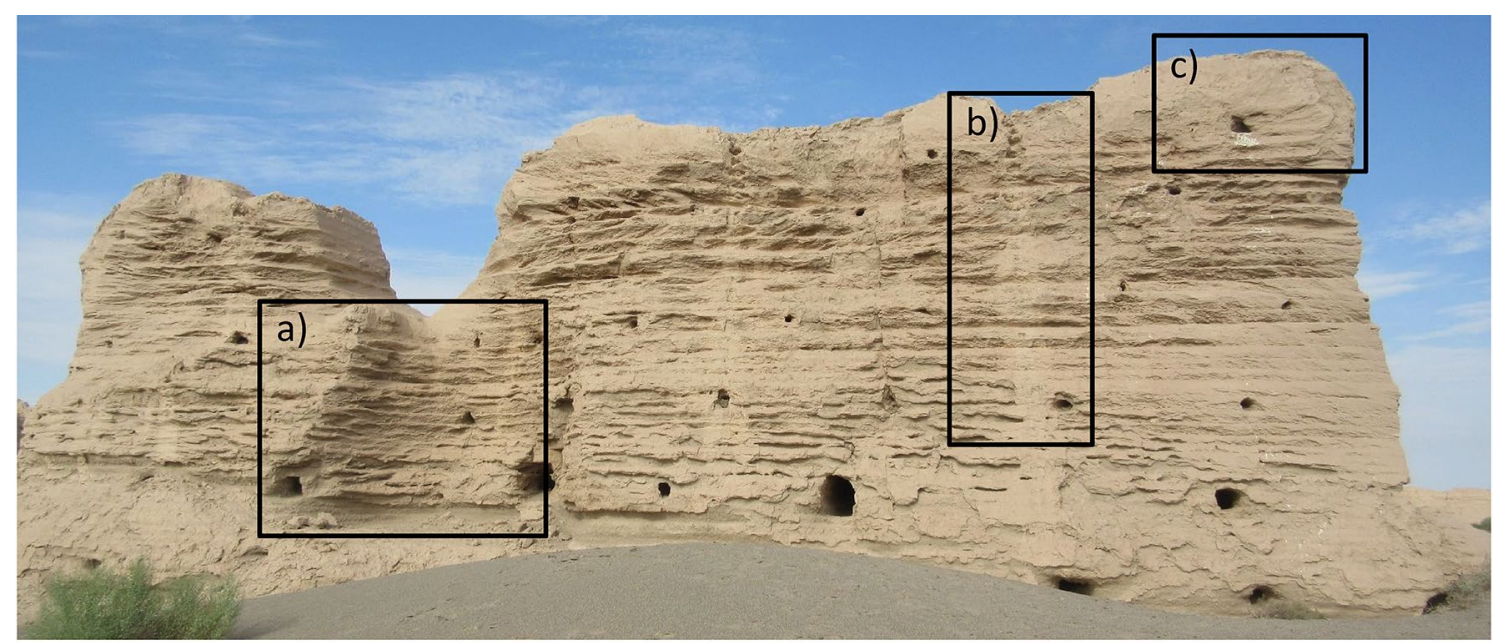

a

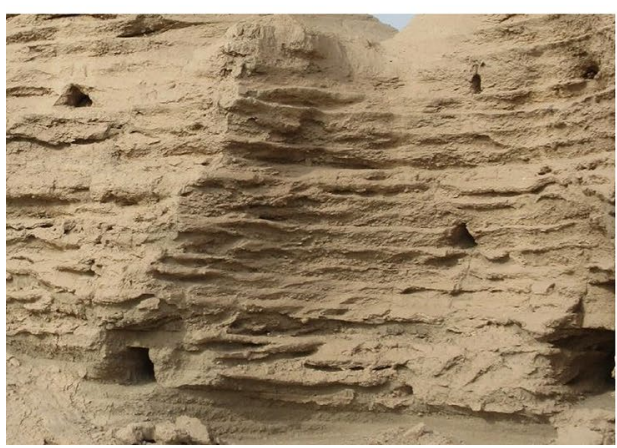

b

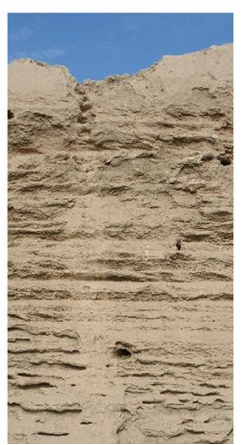

C

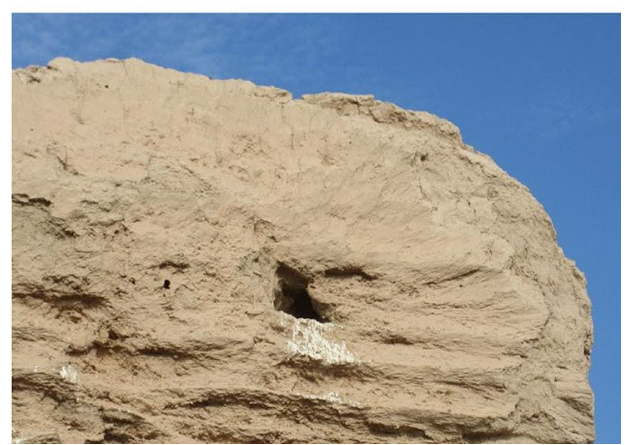

Fig. 5 Examples of deterioration features at Suoyang: a pitting, $\mathbf{b}$ an incipient gully (see Fig. $1 \mathrm{~b}$ for a developed gully) and $\mathbf{c}$ wind polishing

samples in the laboratory, whilst (ii) still being able to control and measure the impact of individual environmental conditions on earthen heritage deterioration, minimising the risks of equifinality that can arise when two different processes may have caused the same deterioration feature to occur. 
For clean wind, previous lab studies identified $12 \mathrm{~m} \mathrm{~s}^{-1}$ as a threshold for deterioration to occur [20]. High accuracy laser scanning in this study showed that deterioration was already occurring on protruding areas at this wind speed resulting in a smoother surface. This decay process was invisible to the naked eye and given the small quantity of sediment eroded, standard methods which capture eroded sediment would have been unlikely to accurately record the eroded material. This suggests that deterioration processes may be occurring at lower speeds than previous thought and that laser scanning could further be used to detect wind driven erosion before it becomes visible. On the historic walls at Suoyang, areas above the saltation layer exhibited features such as polishing on wall tops and rounding of corners (Fig. 5). Interestingly, at $25 \mathrm{~m} \mathrm{~s}^{-1}$ the deterioration caused by clean wind also caused incipient pitting in some concave areas. This suggests that there is likely to be a threshold between 17 and $25 \mathrm{~m} \mathrm{~s}^{-1}$ where clean wind goes from only being able to remove already loose grains of protruding earthen sediment to being able to dislodge more firmly cemented grains [18].

Sediment-laden wind caused notably more deterioration than clean wind. Whilst the uneven distribution of sediment across the test area was not intended, it showed that the concentration of sediment in the wind influences the type of deterioration features that are formed, with winds with high concentrations of sediment causing pitting while winds with low concentrations form polishing features similar to those produced by clean wind (Fig. 4). The highly concentrated sediment laden wind in the upper half of the test area could be representative of deterioration processes occurring in sand storm events or in areas where sediment transportation is high such as at the side of a gap between walls or at the top of a dune that abuts to an earthen wall (Fig. 5). In these areas, pitting features are likely to have formed due to the impact of the kinetic energy of the sand on the earthen material causing particles to be loosened and thus susceptible to being entrained and removed by the wind [18]. The areas subjected to the less highly concentrated sediment-laden wind could represent areas of wall which have depositional elements upwind such as vegetation, minimising the extent of transported sediment that impacts against the wall [38].

Furthermore, the small pitting that occurred on the test area when it was subjected to $12 \mathrm{~m} \mathrm{~s}^{-1}$ sediment-laden wind suggests that the presence of sediment in the wind can significantly increase the amount of deterioration compared to non-sediment laden winds occurring at the same speeds. In addition, the extent of pitting increased with increasing wind speed-in a non-linear fashion for the maximum depth of pitting and in an approximately linear fashion for the area of pitting on the wall surface (Table 2). For low wind speeds, the wind is less likely to be able to fully entrain and transport sediment and any transported sediment which does interact with the historic site will have a low erosivity. Thus, deterioration by lower speed sediment-laden winds is likely to be limited spatially to sections of walls within or just above the saltation zone $[39,40]$, with for example scouring or pitting at the base of walls. High wind speeds are more likely to be able to transport airborne sediment with higher kinetic energy resulting in the wind having a greater erosivity. Consequently, in addition to causing pitting within the saltation zone, faster sediment-laden winds are more likely to cause pitting on higher areas of earthen sites and also cause a faster rate of pitting [18-20].

Wind-driven rain caused significant deterioration by weakening the cemented material between soil particles and transporting material down the face of the wall [3]. The uneven distribution of rain resulted in deterioration being focused around the centre of the spraying area. This meant that initially the central section of the test area was subjected to a high volume of water $\left(>4 \mathrm{~mm} \mathrm{~min}^{-1}\right.$ ) which may not be representative of rainfall events which commonly occur at Suoyang which tend to occur over several hours and produce to up $4 \mathrm{~mm}$ of rainfall. However, according to the Dunhuang Academy, as up to $30 \mathrm{~mm}$ of rainfall has occurred in a single rainfall event at Suoyang, the high volume of water used in the deterioration test could be more reflective of these extreme, high intensity rainfall events. Once an incipient gully started to form, water from other areas of the wall face was also channelled into this gully starting a positive feedback loop that has been observed on gullies at Suoyang during rain events. Additional feedbacks were observed on the test areas, such as the expansion of the wetted material and the deposition of entrained material lower down on the wall face (Fig. 4h, i), which are also found at the historic site (Fig. 5b). Therefore, this suggests that if the surface of a wall at Suoyang is primed with a small fissure, weakness or pre-existing channel, incipient gullies could form after a single high intensity rainfall event, highlighting the high erosivity of rain on earthen heritage that has previously been acknowledged [e.g. 14-16].

However, whilst rain may have caused the greatest amount of erosion to the test wall, the sporadic nature of rain events at Suoyang is likely to limit its impact on deterioration over longer temporal periods (Fig. 6). At Suoyang rain events only occur around 5 times a year and commonly only produce several millimetres of rain over several hours. In contrast, winds of $12 \mathrm{~m} \mathrm{~s}^{-1}$ or faster occurred for a total of 720 h (30 days) between August 


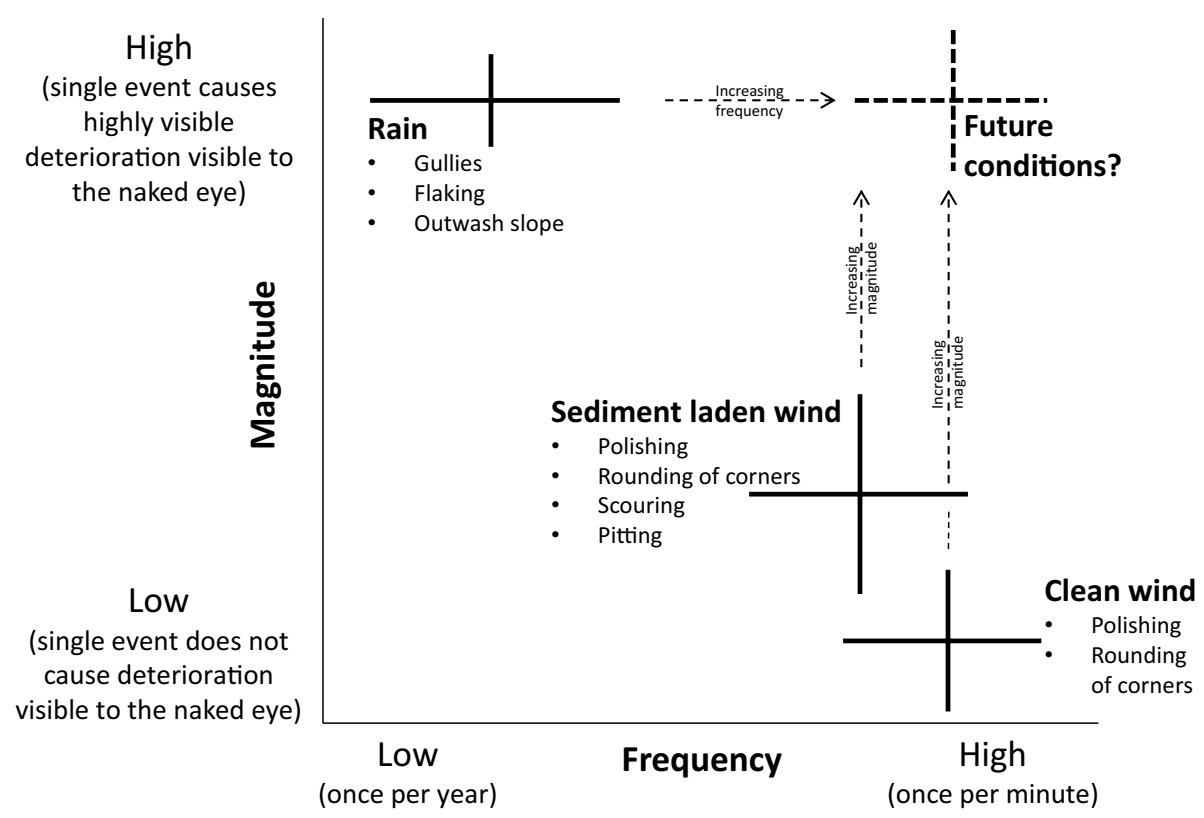

Fig. 6 A conceptual diagram showing the frequency and magnitude of environmental conditions and their associated features on earthen heritage deterioration at Suoyang. The solid crosses show the range of frequencies and magnitudes over which clean wind, sediment laden wind and rain currently operate. The potential impact of future environmental conditions is shown with a dashed cross

2015 and July 2016. This suggests that over an annual period, incipient gullies are likely to form during rain events in areas which have a pre-conditioned fissure or weakness but due to the more frequent nature of wind events, more developed wind polishing features are likely to form on exposed areas of the site. Furthermore, even though winds of $25 \mathrm{~m} \mathrm{~s}^{-1}$ are rare at Suoyang in the open field, only recorded once between August 2015 and July 2016, in gaps between wall sections at Suoyang, the air flow is compressed resulting in wind speeds potentially increasing by $33 \%$ (unpublished data from Suoyang). Therefore, parts of the historic walls around these 'wind tunnel' areas are regularly subjected to significantly higher wind speeds than recorded generally for the site. Sediment laden winds in these areas are likely to significantly contribute to scouring and hollowing within the saltation zone and as extensive hollowing also occurs in these 'wind tunnel' areas above the height of saltation, this suggests that here too, clean wind can cause pitting and hollowing (Fig. 6).

This study shows that earthen heritage deterioration at Suoyang is currently driven by multiple processes which operate over different frequencies and magnitudes and produce notably different deterioration features. However, in north west China the magnitude and frequency of wind and rain events have varied over decadal to centurial timescales [41-43]. Under future climate projections, wind speeds and annual rainfall are predicted to increase in northwest China [44-47], suggesting that rates of deterioration at sites such as Suoyang are likely also to increase. Figure 6 conceptually shows the current frequency and magnitude of clean wind, sediment laden wind and driving rain events at Suoyang but could also be modified to be applied to other earthen heritage sites in semi-arid areas. The current frequency and magnitude of events is based on the limited environmental data collected at Suoyang between 2015 and 2018, and also informed by expert opinion from site managers who have a deep understanding of the local climate. Figure 6 also highlights that the frequency and magnitude of environmental events are not static and suggests how they could be influenced by future projected changes in climate. Increasing (i) the frequency of rain storm events from more than five events on average per year, or (ii) the magnitude of either wind speed events or the amount of sediment transported by the wind would increase the potential erosivity of wind and wind-driven rain, thus increasing the amount of deterioration experienced at Suoyang. For future conservation to be successful, these potential changes in the frequency or magnitude of drivers of deterioration need to be incorporated into the site's management strategies. Further research is needed to understand how projected climatic scenarios could impact the rate and nature of deterioration occurring on earthen heritage and also to understand how environmental forces interact causing synergistic effects $[6,17]$. 
This research into synergistic effects is vital to further allow comparison of results from laboratory and fieldbased studies on earthen deterioration.

\section{Conclusion}

Environmental forces can cause deterioration to earthen heritage. This study utilised a unique opportunity to undertake deterioration experiments at the remote and understudied World Heritage site of Suoyang Ancient City, China. The tests were performed by exposing a test wall to clean wind, sediment-laden wind and wind-driven rain and resulted in the formation of incipient deterioration features which could be mapped on to features seen on the historic walls. Clean wind caused the least deterioration and only removed loose material from protruding areas of the wall, while sediment-laden wind caused pitting. Wind-driven rain caused the greatest deterioration with the formation of incipient gullies down the wall face. However, the low frequency of rainfall at Suoyang is likely to limit the extent to which rainfall can cause deterioration at the site, whereas the almost continual nature of erosive wind events suggests that wind may play an important role in causing deterioration even though it only has a low magnitude impact. The formation of the incipient features suggest that this field based experimental method provides a more realistic deterioration mechanism than using small samples in the laboratory, whilst still being able to control and measure the impact of individual environmental conditions on earthen heritage deterioration. Further research is needed to understand how climate change will affect the environmental forces operating at Suoyang as increases in the frequency of rainfall or the speed of the wind could result in faster rates of earthen heritage deterioration. These findings show that conservation strategies at rammed earth sites need to address the impact of clean wind, sediment laden wind and rain to effectively minimise deterioration.

\author{
Abbreviations \\ PWESD: portable wind erosion simulation device; PRESD: portable rain erosion \\ simulation device.
}

\section{Acknowledgements}

We would like to thank the Dunhuang Academy for the extensive use of their equipment in the field. We are grateful to Hongtao Zhan, Fei Qiu, Fasi Wu, Dongpeng He, Bo Zhang, Jingjing Huang and Wei He for their help, advice and practical assistance they provided throughout the fieldwork period. We are also grateful to Xudong Wang, Qinglin Guo and Qiangqiang Pei for their support with this work.

We would like to thank the four reviewers for their comments on this paper.

\section{Authors' contributions}

Conceptualization, JR and HV; Data curation, JR and GZ; Formal analysis, GZ and JR; Funding acquisition, $\mathrm{HV}$; Investigation, JR, GZ and $\mathrm{HZ}$; Methodology, JR, GZ and HZ; Project administration, HV and HZ; Resources, JR and
HZ; Supervision, HV; Validation, JR, GZ, HV and HZ; Visualization, JR and GZ; Writing —original draft, JR; Writing — review and editing, JR, HV, GZ and HZ. All authors read and approved the final manuscript.

\section{Funding}

This research was funded by UK Engineering and Physical Sciences Research Council (EPSRC) grant for the Centre for Doctoral Training Science and Engineering in Art, Heritage and Archaeology (EP/L016036/1) in association with the Getty Conservation Institute.

\section{Availability of data and materials}

The datasets used and/or analysed during the current study are available from the corresponding author on reasonable request.

\section{Competing interests}

The authors declare that they have no competing interests.

\section{Author details}

${ }^{1}$ Oxford Rock Breakdown Laboratory, School of Geography and the Environment, University of Oxford, Oxford OX1 3QY, UK. ${ }^{2}$ Dunhuang Academy, Dunhuang 736200, China.

Received: 18 February 2019 Accepted: 5 July 2019

Published online: 15 July 2019

\section{References}

1. WHEAP. World Heritage: Inventory of earthen architecture. 2012. http:// unesdoc.unesco.org/images/0021/002170/217020e.pdf. Accessed 20 Jan 2019.

2. PuT, Chen W, Du Y, Li W, Su N. Snowfall-related deterioration behavior of the Ming Great Wall in the eastern Qinghai-Tibet Plateau. Nat Hazards. 2016;84:1539-50.

3. Shao M, Li L, Wang S, Wang E, Li Z. Deterioration mechanisms of building materials of Jiaohe ruins in China. J Cult Herit. 2013;14:38-44.

4. Oliver A. Fort Selden adobe test wall project: phase I: final report. Los Angeles: Getty Conservation Institute; 2000.

5. Velde B. Formation of earthen materials. In: Avrami E, Hubert G, Hardy $M$, editors. Terra literature review an overview of research in earthen architecture conservation. Los Angeles: The Getty Conservation Institute; 2008. p. 15-20.

6. Rainer L. Deterioration and pathology of earthen architecture. In: Avrami E, Guillaud H, Hardy M, editors. Terra literature review an overview of research in earthen architecture conservation. Los Angeles: The Getty Conservation Institute; 2008. p. 45-61.

7. Guerrero L. Deteroriation of heritage built in adobe. Diseño y Soc. 2002;13:4-11.

8. Selwitz C, Coffman R, Agnew N. The getty adobe research project at Fort Selden III: An evaluation of the application of chemical consolidants to test walls. In: Agnew N, editor. Proceedings of 6th international conference conservation earthen architecture. Los Angeles: The Getty Institute; 1990. p. 255-60.

9. Brown PW, Robbins CR, Clifton JR. ADOBE II: factors affecting the durability of adobe structures. Stud Conserv. 1979;24:23-39.

10. Taylor MR. An evaluation of the New Mexico State monuments adobe test walls at Fort Selden. In: Agnew N, editor. Proceedings of 6th international conference conservation earthen architecture. Los Angeles: The Getty Institute; 1990. p. 383-9.

11. Illampas R, loannou I, Charmpis DC. Overview of the pathology, repair and strengthening of adobe structures. Int J Archit Herit. 2013;7:165-88.

12. Du Y, Chen W, Cui K, Gong S, Pu T, Fu X. A model characterizing deterioration at earthen sites of the Ming Great Wall in Qinghai Province. China. Soil Mech Found Eng. 2017;53:426-34.

13. Richards J, Wang Y, Orr S, Viles H, Richards J, Wang Y, et al. Finding common ground between United Kingdom Based and Chinese approaches to earthen heritage conservation. Sustainability. 2018;10:3086.

14. Crosby A. Common sources of deterioration. In: Garrison JW, Ruffner EF, editors. Adobe, Pract Tech Asp Adobe Conserv. Prescott: Heritage Foundation of Arizona; 1983. p. 13-8. 
15. Fodde $\mathrm{E}$, Khan MS. Affordable monsoon rain mitigation measures in the world heritage site of Moenjodaro, Pakistan. Int J Archit Heritage. 2013;11:161-73

16. Bui QB, Morel JC, Reddy BVV, Ghayad W. Durability of rammed earth walls exposed for 20 years to natural weathering. Build Environ. 2009;44:912-9.

17. Brown RB, Sandoval B, M. HO. The protection and conservation of the adobe structures at Paquimé, Casas Grandes, Chihuahua, Mexico. In: Grimstad K, editor. In: 6th Int Conf Conserv Earthen Archit Adobe 90 Prepr. Marina del Rey, CA: Getty Conservation; 1990. p. 204-8.

18. Mao X, Zhoa D, Zhang W. Experimental study on the effects of wind erosion and reinforcement for the rammed soil. J Xi'an Univ Archit Technol (Natural Sci Ed). 2015;47:555-9.

19. Mao X, Zhao D, Chen P, Hou W. Consolidation experiment on earthen architecture site in arid region. Yanshilixue Yu Gongcheng Xuebao/Chinese J Rock Mech Eng. 2008;27:7-11.

20. Wang XD, Zhang HY, Yan GS, Pei QQ. Durability of ancient earthen architecture under wind erosion in the Milan Ancient City along the Silk Road of China. Adv Mat Res. 2011;163-167:3230-6.

21. Lombillo I, Villegas L, Fodde E, Thomas C. In situ mechanical investigation of rammed earth: calibration of minor destructive testing. Constr Build Mater. 2014;51:451-60.

22. Haines-Young RH, Petch JR. Multiple working hypotheses: equifinality and the study of landforms. Trans Inst Br Geogr. 1983;8:458-66.

23. Lercari N. Monitoring earthen archaeological heritage using multi-temporal terrestrial laser scanning and surface change detection. J Cult Herit. 2019 (in press)

24. Campiani A, Lingle A, Lercari N. Spatial analysis and heritage conservation: Leveraging 3-D data and GIS for monitoring earthen architecture. J Cult Herit. 2019 (in press)

25. Matero F, Moss E. Temporary site protection for earthen walls and murals at Çatalhöyük, Turkey. Conserv Manag Archaeol Sites. 2004;6:213-27.

26. Sun L-D, Zhang H-Y, Zhao H-Y, Lin J-J, Qu W. Features of climate change in Northwest China during 1961-2010. Adv. Clim. Change Res. 2013:4:12-9.

27. Selwitz C. Saving the Fort Selden ruins: the use of a composite blend of chemicals to stabilize fragile historic adobe. Conserv Manag Archaeol Sites. 1995;1:109-16.

28. Peng $X$, Shi W, Hua C. Study on the mechanism and loss of erosion by wind driven rain for rammed earth buildings. Sichuan Daxue Xuebao (Gongcheng Kexue Ban)/Journal Sichuan Univ (Engineering Sci Ed). 2015:47:105-11.

29. Belnap J, Gillette DA. Disturbance of biological soil crusts: impacts on potential wind erodibility of sandy desert soils in southeastern Utah. L Degrad Dev. 1997:8:355-62.

30. Belnap J, Gillette DA. Vulnerability of desert biological soil crusts to wind erosion: the influences of crust development, soil texture, and disturbance. J Arid Environ. 1998;39:133-42.

31. Belnap J, Phillips SL, Herrick JE, Johansen JR. Wind erodibility of soils at Fort Irwin, California (Mojave Desert), USA, before and after trampling disturbance: implications for land management. Earth Surf Process Landforms. 2007;32:75-84.

32. Li X-Y, Liu L-Y, Wang J-H. Wind tunnel simulation of aeolian sandy soil erodibility under human disturbance. Geomorphology. 2004;59:3-11.

33. Eldridge DJ, Leys JF. Exploring some relationships between biological soil crusts, soil aggregation and wind erosion. J Arid Environ. 2003;53:457-66.

34. Barton J. 3D laser scanning and the conservation of earthen architecture: a case study at the UNESCO World Heritage Site Merv, Turkmenistan. World Archaeol. 2009;41:489-504.

35. Barnard H, Wendrich WZ, Winkels A, Bos JEMF, Simpson BL, Cappers RTJ. The preservation of exposed mudbrick architecture in Karanis (Kom Aushim), Egypt. J F Archaeol. 2016;41:84-100.

36. Bruno A, Bultinck G, Chiari G, Trossarelli C. Contributions to the study of the preservation of mud-brick structures. Mesopotamia. 1968;69:445-79.

37. Clifton JR. Preservation of historic adobe structures: a status report. Washington: NBS Tech; 1977.

38. Wolfe SA, Nickling WG. The protective role of sparse vegetation in wind erosion. Prog Phys Geogr. 1993;17:50-68.

39. Kok JF, Parteli EJR, Michaels TI, Karam DB. The physics of wind-blown sand and dust. Reports Prog Phys. 2012;75:106901.

40. Williams $\mathrm{G}$. Some aspects of the eolian saltation load. Sedimentology. 1964;3:257-87

41. Zhang $P$, Cheng $H$, Edwards RL, Chen F, Wang Y, Yang $X$, et al. A test of climate, sun, and culture relationships from an 1810-year Chinese cave record. Sci Am Assoc Adv Sci. 2008;322:940-2.

42. Deng Y, Gou X, Gao L, Yang M, Zhang F. Tree-ring recorded moisture variations over the past millennium in the Hexi Corridor, northwest China. Environ Earth Sci. 2017;76:272

43. Yang B, Qin C, Bräuning A, Burchardt I, Liu J. Rainfall history for the Hexi Corridor in the arid northwest China during the past 620 years derived from tree rings. Int J Climatol. 2011;31:1166-76.

44. Shi Y, Shen Y, Kang E, Li D, Ding Y, Zhang G, et al. Recent and future climate change in northwest China. Clim Change. 2007;80:379-93.

45. Wang R, Cheng Q, Liu L, Yan C, Huang G, Wang R, et al. Multi-model projections of climate change in different RCP scenarios in an Arid Inland Region. Northwest China. Water. 2019;11:347.

46. Guo J, Huang G, Wang X, Li Y, Lin Q. Investigating future precipitation changes over China through a high-resolution regional climate model ensemble. Earth's Futur. 2017;5:285-303.

47. Jiang Y, Luo Y, Zhao Z, Shi Y, Xu Y, Zhu J. Projections of wind changes for 21 st century in China by three regional climate models. Chin Geogr Sci. 2010;20:226-35.

\section{Publisher's Note}

Springer Nature remains neutral with regard to jurisdictional claims in published maps and institutional affiliations.

\section{Submit your manuscript to a SpringerOpen ${ }^{\odot}$ journal and benefit from:}

- Convenient online submission

- Rigorous peer review

- Open access: articles freely available online

- High visibility within the field

Retaining the copyright to your article

Submit your next manuscript at springeropen.com 